\title{
An internal combustion engine without a crankshaft. Perspectives
}

The article examines the level of perfection of the modern internal combustion engine design, their impact on the environment and population. A new engine concept has been developed. As a result a decrease in fuel consumption by $80 \%$ has been discovered as well as the effects of the new engine in the field of ecology such as a decrease in the number of diseases caused by poor environmental conditions, a lower risk of global warming, lower health care costs, an increase in life expectancy, etc. Also, for countries with fossil fuel deposits, can be anticipated dropping treasury income, factory closures, high unemployment, the likelihood of protests and uprisings.

Key words: engine, fuel efficiency, global warming, pollution

\section{Global warming and pollution}

The growing population of the world is an objective phenomenon and it has a strong relationship with such phenomena as, on the one hand, pollution of the air, water and land, starvation, spread of diseases, etc., and, on the other hand, the demand for energy from different sources to prevent the above-mentioned pollution, starvation, spread of diseases, etc. This means that the more goods and food are produced and services provided, the more pollution, including $\mathrm{CO}_{2}$, will be thrown into the environment and the faster the temperature will increase.

This issue is alarming and attracts the attention of national governments and international organizations.

NASA has published the latest measurements on July 2020 - 414 ppm and chart "Direct measurement: 2005present" [1].



Fig. 1. Direct measurement: 2005-present [1]

It is easy to see that global warming is getting worse and could be described by an equation. It means that using this equation we can anticipate the levels of global temperature and carbon dioxide in the near future and beyond. It is well known that the burning of 1 liter of gas produces about 2 kilos of $\mathrm{CO}_{2}$ [2]. It is easy to count, but, honestly, scary.

So far, a huge amount of work has been done with noticeable results in reducing the level of $\mathrm{CO}_{2}$ and pollution. For example, new sources of biofuels such as wood, soybeans, algae, sugar cane, palm oil and rape oil seeds have demonstrated that they are applicable, but actually didn't solve the problem.

An idea to replace ICE by an electric vehicle powered by batteries looks like an attempt to mislead. EV advocates claim that EV will be fuelled by renewables sources, such as wind and solar but they always forget to say that accord- ing to research of BP a part of they are only 3-5\% world's energy supply [3].

A research of $\mathrm{BP}$ also shown, that the total part of the fossil fuels like oil and gas in all primary sources of power is about $60 \%$ and coal $20 \%$ [3].

At the same time the UN has made step to limit GHG. The United Nations Framework Convention on Climate Change (UNFCCC) entered into force on 21 March 1994 and set a goal "to stabilize greenhouse gas concentrations "at a level that would prevent dangerous anthropogenic (human induced) interference with the climate system" and "such a level should be achieved within a time-frame sufficient to allow ecosystems to adapt naturally to climate change, to ensure that food production is not threatened, and to enable economic development to proceed in a sustainable manner [4]".

It means that in the foreseeable future the main roles in the development and prosperity of the whole world will be played by the internal combustion engine and fossil fuels. Moreover "IJER editorial: The future of the internal combustion engine" defined the problem clearly -"The $\mathrm{CO}_{2}$ emitted from an engine is directly proportional to the hydrocarbon fuel consumed" [5]. Therefore, there is the vital requirement to find a new approach in reducing fuel consumption and, therefore, carbon dioxide emissions.

\section{An internal combustion engine without a crankshaft}

The research shown that the main directions to reduce emission are "advanced combustion modes and innovative after-treatment systems, including extensive use of catalysts and high-filtration-efficiency diesel and gasoline particulate filters (D/GPF) in the aftertreatment system, while the use of urea injections and selective catalytic reduction (SCR)" [5]. However, another path and a critical look at traditional internal combustion engines also deserve an attention.

Modern internal combustion engines are built using the classical design: cylinder, piston, connecting rod and crankshaft, and we should note a number of known flaws in traditional engines:

Inefficient combination of pressure within the cylinder and tangential force on the crankshaft.

Two points need to be looked at closely here:

a) With the pressure increasing to a maximum and combustion of a significant part of the mixture, the crankshaft rotates 180 degrees, and the ratio of the tangential force on 
the crankshaft to the force acting on the piston varies from 0 to 1 and from 1 to 0 .

Thus, two phenomena are observed when the crankshaft rotates 180 degrees:

- the pressure changes from a maximum to a minimum value (Fig. 2), which coincides with an isothermal part (combustion stroke) of the Carnot cycle [6].

A polytropic process is [7]:

$$
\mathrm{P} \cdot \mathrm{V}^{\mathrm{n}}=\mathrm{const}
$$

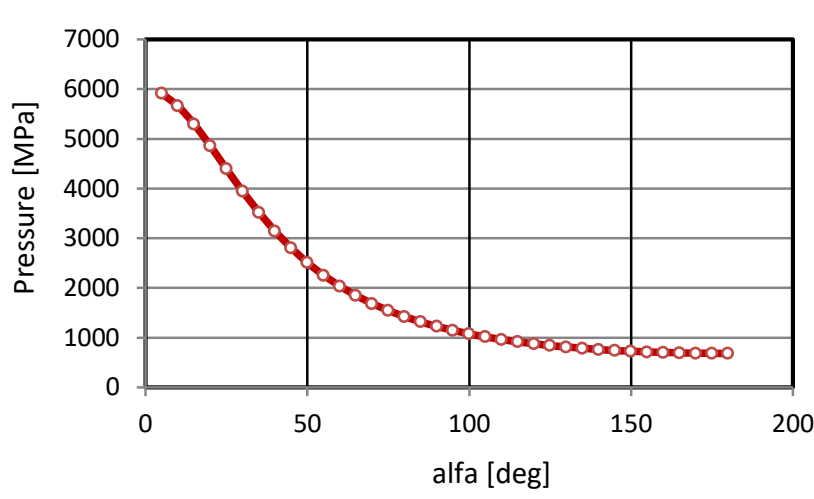

Fig. 2. A change in pressure when a shaft turns from 0 to 180 degrees

- the tangential force on the crankshaft changes from 0 to 1 and from 1 to 0 (Fig. 4) [8]:

$$
\mathrm{T}=\mathrm{P} \cdot \sin (\mathrm{a}+\mathrm{B}) / \cos \mathrm{B}(\text { Fig. } 3)
$$

$\mathrm{P}=1$ - force acting on the piston (conventionally assumed equal to 1$), \mathrm{T}$ - tangential force.

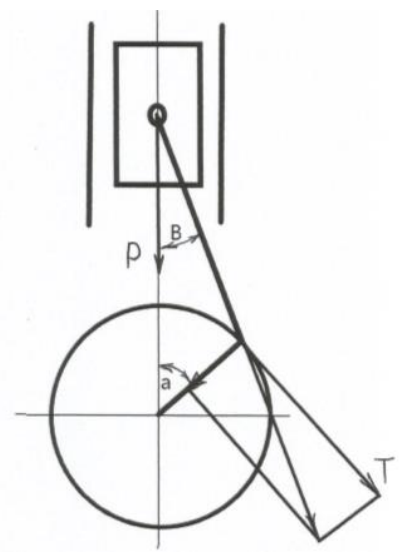

Fig. 3. A crank mechanism

b) The compressed mixture is ignited when the piston is at TDC. It is known that high temperature and high pressure are necessary for the complete and effective combustion of the air-fuel mixture. This condition is violated in traditional engines. After passing the TDC, the piston goes down. The space above the piston increases, and the pressure and temperature decrease, and the fuel-air mixture does not burn up completely.

"Ideally, if the combustion process is complete, the exhaust gases should only be carbon dioxide $\left(\mathrm{CO}_{2}\right)$ and water vapour $\left(\mathrm{H}_{2} \mathrm{O}\right)$. In reality, mainly due to incomplete combustion, the exhaust gases also contain pollutant emissions: oxides of nitrogen $\left(\mathrm{NO}_{\mathrm{x}}\right)$, unburnt hydrocarbons $(\mathrm{HC})$, carbon monoxide (CO), soot's/particles (PM), polyaromatics, aldehydes ketones and nitro-olefins" [9].

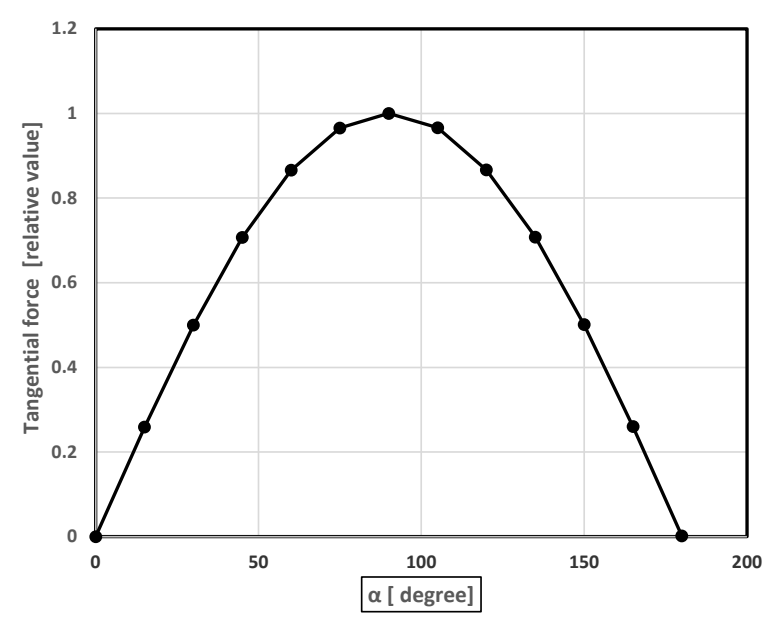

Fig. 4. Changes of a tangential force when crankshaft turns 180 degrees

Therefore, we need to define a goal to overcome the above-mentioned flaws, namely, to create a new concept of an internal combustion engine.

Three tasks need to be solved.

1. The lever of tangential force on the drive shaft must be constant along the piston's entire travel path.

2. At the TDC the piston has to be stationary for a short time to ensure an increase of the pressure and temperature till the optimal values and also at the BDC to ensure the exhaust of the entire amount of burned gas.

3. The fresh fuel-air mixture should not mix with the remnants of the combusted mixture.

The idea of the new engine concept is to replace the crankshaft by gear racks that move linearly and drive the gear wheels (sprockets) creating torque.

Two videos show the new engine (YouTube. Serguei Tikhonenkov - "Engine of an internal combustion without a crankshaft", "2-strokes engine without a crankshaft. Every stroke is combustion").

The engine (Figs 5-7) can contain from 1 (YouTube. Serguei Tikhonenkov "Engine of an internal combustion without a crankshaft") to 2 or 4 units; optimally - 4 (YouTube. Serguei Tikhonenkov "2-stroke engine without a crankshaft. Every stroke is combustion”).

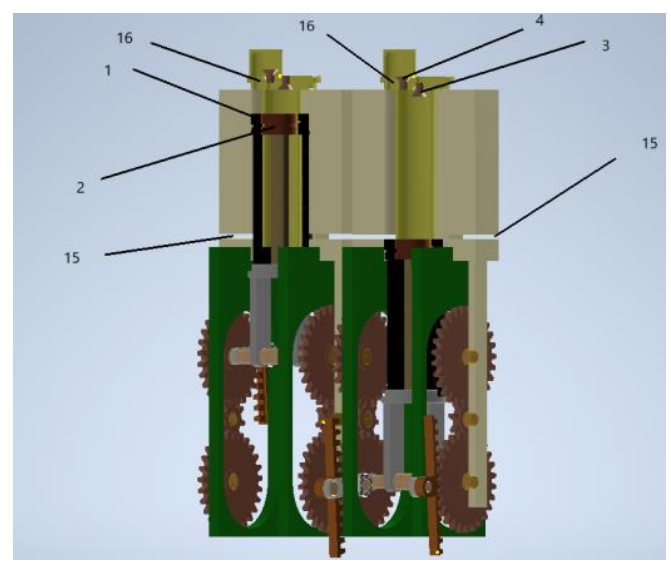

Fig. 5. 2-stroke engines without crankshaft 


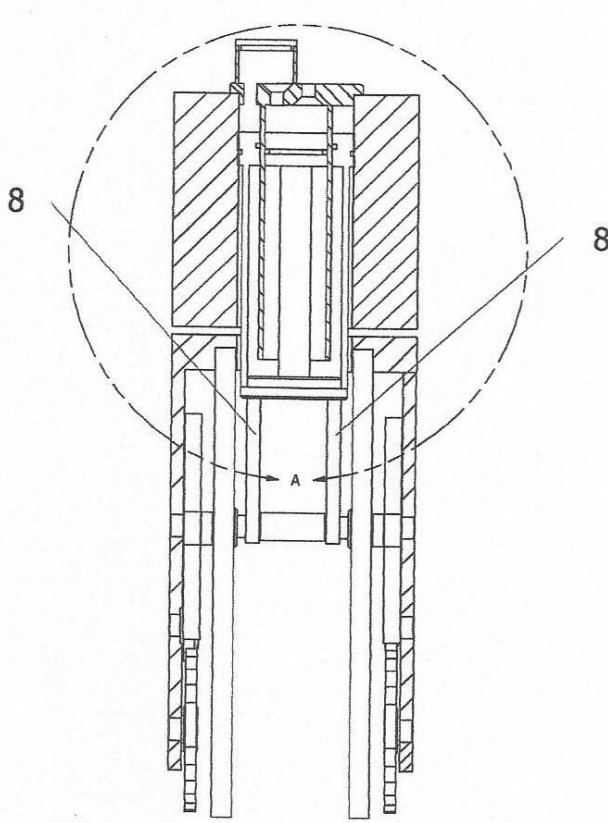

Scale $1: 2$

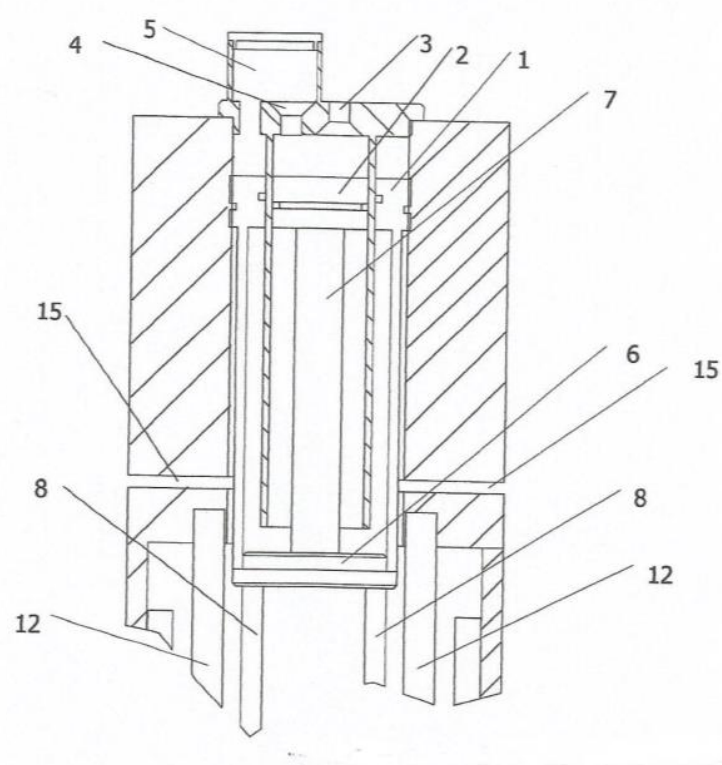

Detail A from Fig. 6 (left)

Fig. 6. Engine details of an internal combustion without a crankshaft
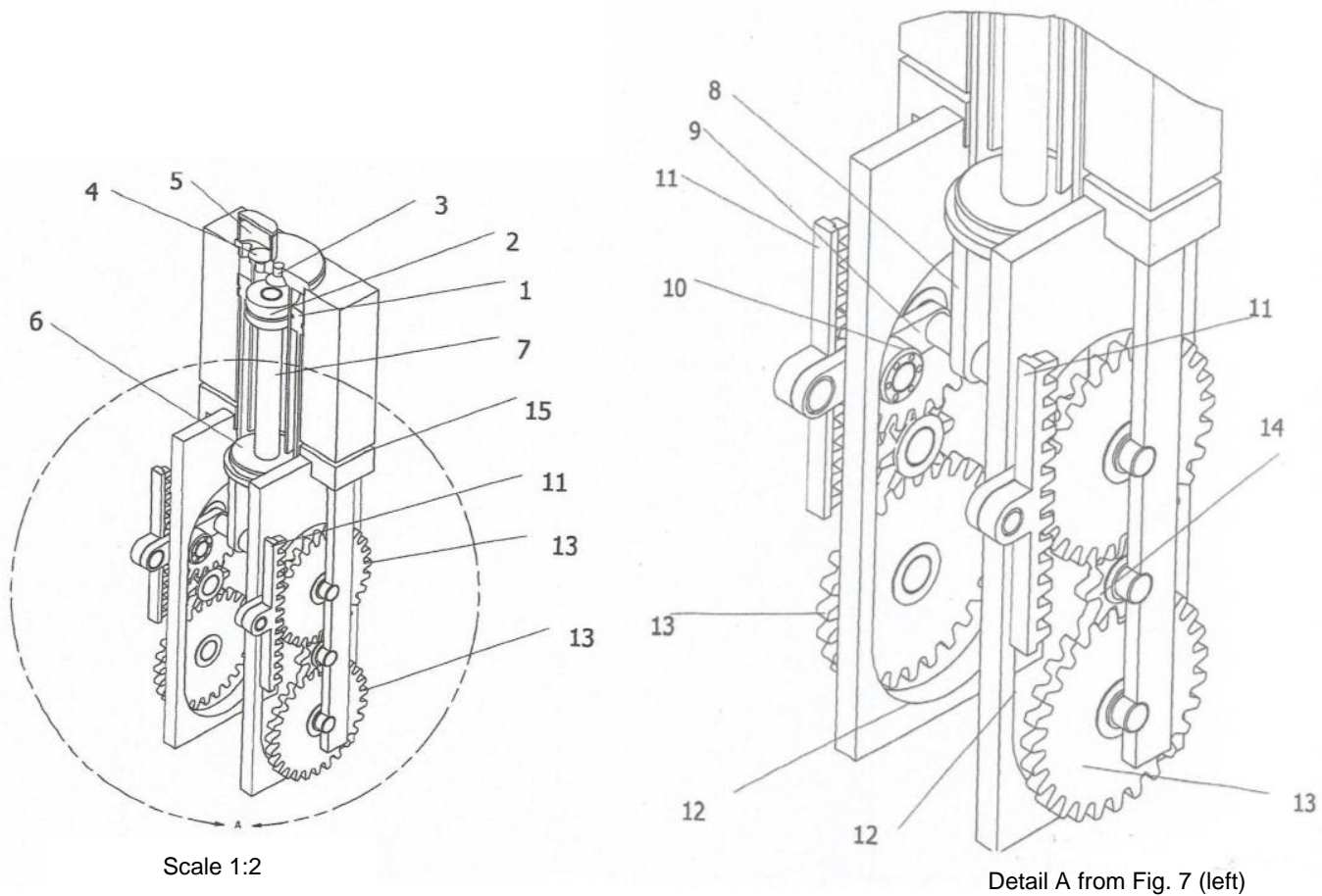

Fig. 7. View of engine (left) and details of an engine (right)

Each unit consists of a main 1 and additional 2 cylinders, an intake valve 3 and a valve 4 connecting the cavities above piston of the main 1 and piston of the additional 2 cylinders, a common chamber 5 , a base 6 , on which piston of cylinder 1 and rod 7 of piston of cylinder 2 are mounted, and on the lower part of the base 6 there are two struts 8 . On each strut 8 there are pivotally mounted levers 9 with rollers 10 and gear racks 11 fixed onto them. The rollers 10 roll along the guides 12 and the gear racks 11 interact with the gear wheels 13 (sprockets) connected by a pinion 14. In the bottom part of the block apertures 15 for exhaust gases are located. The common chamber 5 and the cavity above the piston of the main cylinder 1 are connected by a channel 16.

The engine operates as follows. When the working mixture is ignited above piston of the main cylinder 1, valve 4 is closed by pressure. The pressure makes the piston of the main cylinder 1 and the base 6 move down. At the same 
time, the rod 7 and the piston of the additional cylinder 2 move downward, while the valve 3 is opened by vacuum and ensures the intake of the combustible mixture. The levers 9 mounted on the struts 8 also move down. At the same time, the rollers 10 run along the guides 12 , and the gear racks 11 drive the gears wheels (sprockets) 13, creating torque. When piston of the cylinder 1 reaches its extreme low point, the exhaust gases are discharged through openings 15. At this point the sprockets make the gear racks to rotate a 180-degree arc around the sprockets due to their inertial forces and interaction with the attached units. After that the base 6 and the pistons of the cylinders 1 and 2 installed on it are moved upward also due to inertial forces and interaction with the attached units. When moving upward, the mixture entering the cavity above piston of the additional cylinder 2 moves through the valve 4 which is opened by pressure, the common chamber 5 and the channel 16 into the cavity above piston of the main cylinder 1 . Now valve 3 is closed by pressure above the piston of the additional cylinder 2 . Thus, compressed combustible mixture is created in the cavity above the piston of the main cylinder 1 . When the mixture is ignited, the cycle repeats.

\section{Differences between the new engine and the traditional one}

At the TDC, the piston is stationary while the gear racks run around a 180-degree arc on a sprocket. At this moment, the fuel-air mixture in the space above the main piston ignites. The volume in this case will be kept constant, which will lead to a many-fold increase in pressure and temperature. These parameters can reach values at which engine failure will occur. This means that the moment of ignition of the fuel-air mixture must be optimized. Optimization will allow us to avoid the destruction of the engine and, at the same time, create a significantly increased pressure above the piston.

Engine power (HP) is defined by an equation [10]

$$
\mathrm{HP}=\mathrm{n} \cdot \mathrm{M}
$$

where: $\mathrm{M}$ - torque on the shaft, $\mathrm{n}$ - revolutions per minute,

$$
\mathrm{M}=\mathrm{T} \cdot \mathrm{L}
$$

where: $\mathrm{L}-\mathrm{a}$ size of the lever on the shaft, $\mathrm{T}-$ tangential force.

Force acting on the piston:

$$
\mathrm{P}=\mathrm{S} \cdot \mathrm{F}
$$

where: $\mathrm{S}$ - area of the piston, $\mathrm{F}$ - value of pressure in the cylinder.

Therefore, in the new concept of the engine the temperature and pressure will be increased because piston is stationary during the calculated short time at the TDC.

It means that the pressure and temperature in the engine and as well the power depend on the time of the pistons delay at the TDC. This is a functional relationship.

$$
\mathrm{HP}, \mathrm{P}, \mathrm{T}=\mathrm{f}(\mathrm{t})
$$

where: $\mathrm{t}$ - time of the delay.

The advantage of the new engine compared with the traditional one is demonstrated in Fig. 8. Figures $8 \mathrm{a}$ and $8 \mathrm{~b}$ clearly show that equal amounts of fuel for both engines are used more efficiently in the new one (Fig. 8b, red). In the new engine, due to the time delay, the pressure and temperature are significantly higher than in the traditional one. It means, that the HP of the new engine with the same $n$ will be more in the same scale.

At the same time as we know the efficiency of any machine is defined by the coefficient efficiency [11]:

$$
\eta=\left(\mathrm{T}_{\mathrm{h}}-\mathrm{T}_{\mathrm{c}}\right) / \mathrm{T}_{\mathrm{h}}
$$

where: $T_{h}$ - heater temperature, $T_{c}-$ cooler temperature.

It means, that an efficiency of the new engine will be higher than in the traditional one.

At the bottom dead center (BDC), the piston is stationary, same as at TDC, while the gear racks run around a 180degree arc on sprockets providing a high level of exhaust. As a result, this means that fresh fuel-air mixture will not mix with the remnants of the combusted mixture. In the proposed engine, the working stroke and the injection stroke are performed simultaneously, both strokes being isolated. While the pistons of the main 1 and additional 2 cylinders are moving up, the fresh fuel-air mixture is pumped by the piston of the additional cylinder 2 into the space above the piston of the main cylinder 1 through the valve 4 which is opened by pressure, the common chamber 5 and the channel 16 .

In the proposed engine the lever of tangential force on the drive shaft remains constant along the piston's entire travel path (Fig. 9).
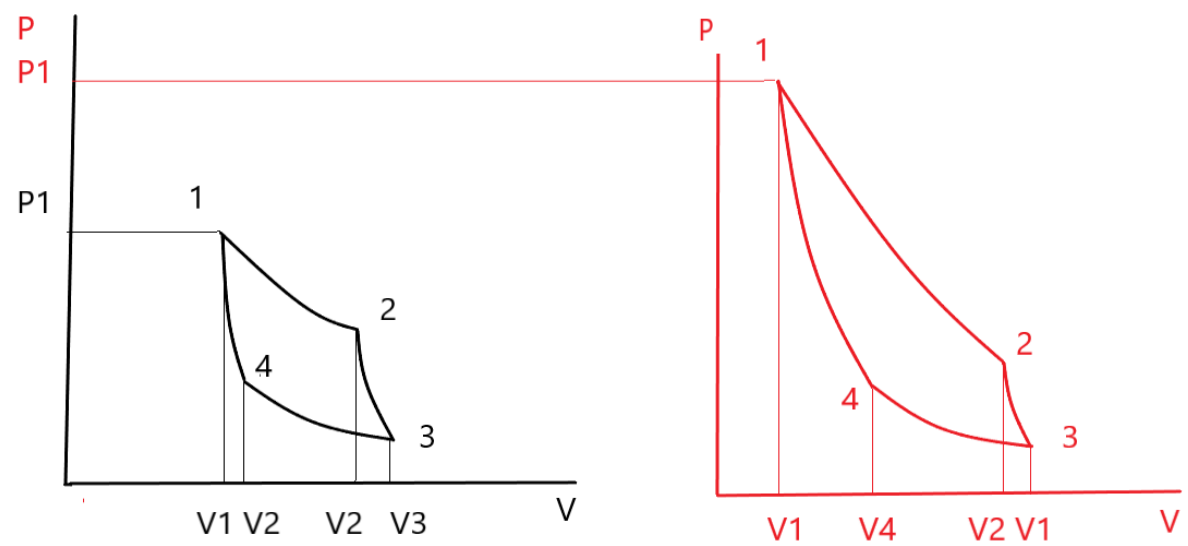

Fig. 8. Cycle: a) in the traditional engine, b) in the new engine 


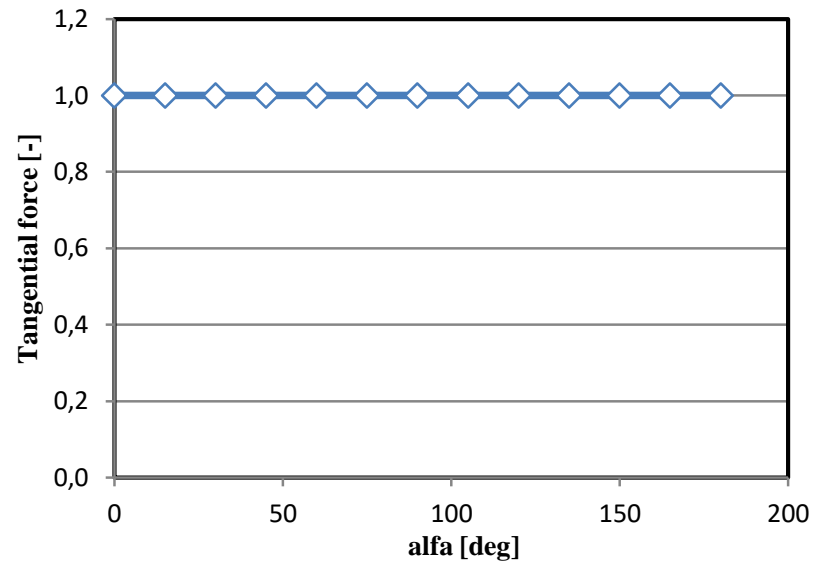

Fig. 9. A tangential force when a shaft turns from 0 to 180 degrees

$\mathrm{T}=\mathrm{P}$

$\mathrm{P}=1$ - force acting on the piston (conventionally assumed equal to 1$)$.

The change in torque values in the proposed engine is determined only by the change of pressure in the cylinder. Statistical values of moment variations in the proposed engine and in an engine with a crankshaft are characterized by arithmetic averages. The arithmetic average of the moment in the proposed engine is 1.83 times the arithmetic average of the moment in the traditional engine (Fig. 10).

So, it is possible to say, that the proposed engine provides the significantly reduced fuel consumption and a perfection of the fuel process's burn.

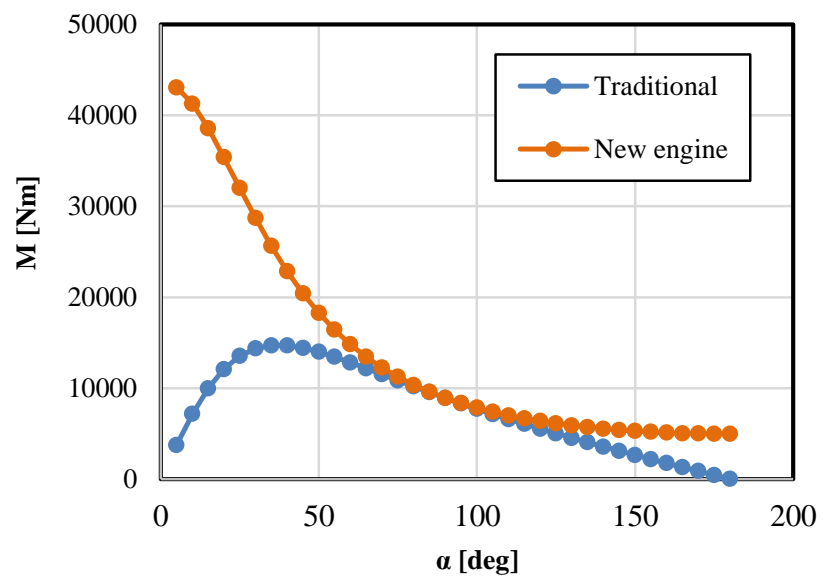

Fig. 10. Variation of the moments in the new engine and traditional one

The new engine must be equipped with efficient flywheels to compensate for the uneven rotation.

We should also note that there are no camshafts and the gas distribution mechanism.

"Valve mechanism system is one of more system which influence of characteristic and performance an engine. To changes or other word is modification a working cycle, it's means changes control system in the work cycle. Control system in an engine is valve mechanism system. To be changes a mechanism it's means to be changes control component design of that mechanism. Control component in a valve mechanism system is camshaft" [12].

The gas distribution mechanism, which includes a camshaft, is a rather complex unit and has some flaws.

In some researches are noted, that "line contact between existing cam and follower mechanism results in high frictional losses which results in low mechanical efficiency" [13].

In traditional engines cams are a type of lobe and as they spin the intake and exhaust valves are opened. But due to the design of the gas distribution mechanism, the phases of the intake and exhaust valves overlap. This causes the fresh portion to mix with the unburned mixture.

In Figure 11 presented displacement diagrams for valves (exhaust 1 and intake 2) in the traditional engine, in the proposed one (intake 3 or connecting 4) and an area of aperture 15 for exhaust in the proposed engine. In the traditional engines the valve opening area changes from 0 to maximum and from maximum to 0 during the piston movement. The exhaust starts from the end of the combustion stroke and finishes at beginning of the intake stroke. The intake starts from the end of the exhaust stroke and finishes at the beginning of the compression. In the proposed engine the valves (intake valve 3 and connecting valve 4 ) are opened by pressure instantly. The valve (intake or connecting) area in the proposed engine is about 1.35 times the intake valve area in the traditional one.

An exhaust gas releases through apertures 15 when piston of the main cylinder 1 is in the extreme low point. The effective aperture area 15 is many times the area of the exhaust valve in traditional engines (see Fig. 5).

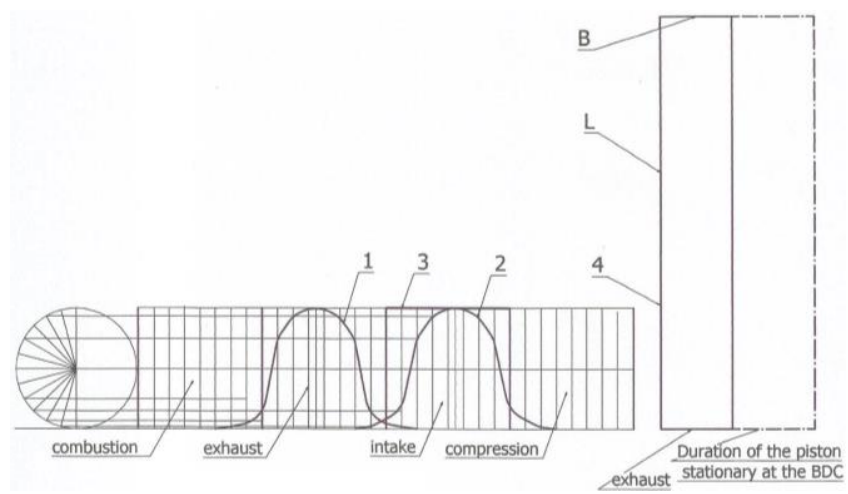

Fig. 11. Displacement diagram of valves: 1 - displacement diagram and an effective area of the exhaust valve in the traditional engines, 2 - displacement diagram and an effective area of the intake valve in the traditional engine, 3 - displacement diagram and an effective area of the intake (connecting) valve in the proposed engine, 4 - an affective area of aperture for exhaust and exhaust duration when the piston is stationary at the BDC, $\mathrm{L}$ - length of apertures, B - width of apertures

\section{Conclusions}

1. Fuel consumption is reduced due to two reasons:

a) Due to that the gear racks move linearly and provide the lever of tangential force on the drive shaft constant along the pistons entire travel path. In result, the arithmetic average of the moment in the proposed engine is 1.83 times the arithmetic average of the moment in the traditional engine.

b) Due to the time delay at the TDC, the pressure and temperature are significantly higher than in the traditional 
one. It can be assumed that an optimization of the delay will increase the pressure by at least $20-30 \%$. It means, that the HP of the new engine will be more than in the traditional one in the same scale using equal amounts of fuel for both engines.

2. Improved exhaust and fuel combustion process.

a) Due to delay at the BDC the time for exhaust increases many-fold. This means that fresh fuel-air mixture will not mix with the remnants of the combusted mixture.

b) The combustion stroke and the injection stroke are performed simultaneously, both strokes being isolated. More over the compression stroke is isolated also.

c) The absence of the gas distribution mechanism, including a camshaft, means that the pressures in cylinders 1 and 2 make "opening" and "closing" of the valves 3 and 4 and aperture 15. This design provides more efficient "intake" and "exhaust" compared to the gas distribution mechanism.

\section{Perspectives}

First of all, it is a huge step in the field of ecology. Reducing fuel consumption will reduce the water, land and air pollution on the same scale. As a result, we can anticipate a decrease in the number of diseases caused by poor environmental conditions, a lower risk of global warming, lower health care costs, an increase in life expectancy, etc. And second, but not last, for example, the new engines connected to generators will force out nuclear and thermal power stations working on coal. Small household electric generators will allow the cheap electricity to be used for heating the home, providing hot water and operation of home appliances, etc.

It is difficult to imagine a general picture of the consequences of using the new engine. Multiple correlations of causes and effects can be described in an economic/mathematical model.

\section{Nomenclature}

$\mathrm{P}$ force acting on the piston

HP horse power

$\mathrm{F} \quad$ pressure in the cylinder

M torque on the shaft

n engine speed

L a size of the lever on the shaft area of the piston tangential force cooler temperature heater temperature coefficient efficiency

\section{Bibliography}

[1] Carbon dioxide. Latest measurement: July 2020. NASA. Global climate change. Vital Sings of the Planet. https://climate.nasa.gov/vital-signs/carbon-dioxide/

[2] Learn the facts: Fuel consumption and $\mathrm{CO}_{2}$. Natural Resources Canada. Published 2014.

https://www.nrcan.gc.ca/sites/www.nrcan.gc.ca/files/oee/pdf /transportation/fuel-efficienttechnologies/autosmart_factsheet_6_e.pdf

[3] BP. Primary energy. 2019. www.bp.com/en/global/corporate/energy-economics/statisticalreview-of-world-energy/primary-energy.html

[4] What is the United Nations Framework Convention on Climate Change? United Nations Framework Convention on Climate Change. 21 March1994. https://unfccc.int/processand-meetings/the-convention/what-is-the-united-nationsframework-convention-on-climate-change

[5] REITZ, R.D., OGAWA, H., PAYRI, R. et al. IJER editorial: The future of the internal combustion engine. International Journal of Engine Research. 2019, 21(1), 3-10. https://journals.sagepub.com/doi/10.1177/1468087419877990

[6] CARSTENSEN, J. Thermodynamics and kinetics. Lecture at the Faculty of Engineering University of Kiel. www.tf.unikiel.de/matwis/amat/td_kin_i/kap_1/backbone/r_se31.html

[7] What is Polytropic Process - Definition. Thermal Engineering. 2020.

https://www.thermal-engineering.org/what-is-polytropicprocess-definition

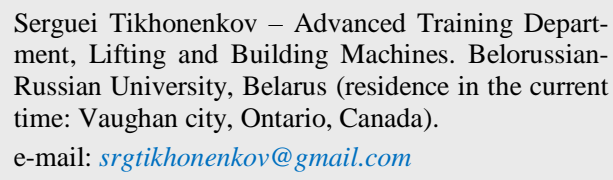

[8] GOTZ, A.N. Kinematics and dynamics of the crank mechanism of piston engines. Vladimir State University. Vladimir 2006.

http://window.edu.ru/resource/807/65807/files/dinamika.pdf

[9] Engine combustion process explained. X-engineer. 2020. $\mathrm{X}$-engineer.org/automotive-engineering/internal-combustionengines/performance/engine-combustion-process-explained/

[10] Power and Torque. EPI Inc. Expertise + Integrity = Performance. 2020.

www.epieng.com/piston_engine_technology/power_and_torque.htm

[11] The Carnot Efficiency. PennState. College of Earth and Mineral Sciences. www.e-education.psu.edu/egee $102 /$ node/1942

[12] RUDY, P.C., NOVIYANTO, T. Design and manufacture camshaft for Otto cycle modification to reducing fuel consumption. International Journal of Development Research. 2017, 7(12), 17398-174022017. https://www.journalijdr.com/sites/default/files/issuepdf/9136.pdf

[13] MALI, M., MASKAR, P., GAWANDE, S. et al. Design optimization of cam \& follower mechanism of an internal combustion engine for improving the engine efficiency. Modern Mechanical Engineering. 2012, 2(3), 114-119. https://doi.org/ 10.4236/mme.2012.23014 